\title{
Molecular characterization of Fasciola isolates collected from sheep, goats and cattle in Kisumu, Baringo and Narok Counties, Kenya
}

Cornelius Kibet Kipyegen ( $\square$ ckyegen@yahoo.com )

Egerton University - Njoro Campus: Egerton University https://orcid.org/0000-0003-3097-1150

Charles I. Muleke

Egerton University - Njoro Campus: Egerton University

Elick O. Otachi

Egerton University - Njoro Campus: Egerton University

\section{Research Article}

Keywords: Fasciola, ITS1, ITS 2, PCR, Fasciolosis, Kenya

Posted Date: November 5th, 2021

DOI: https://doi.org/10.21203/rs.3.rs-930890/v1

License: (c) (i) This work is licensed under a Creative Commons Attribution 4.0 International License. Read Full License 


\section{Abstract}

Fasciolosis is a neglected trematode infection of public health and veterinary importance caused by Fasciola gigantica and Fasciola hepatica. Molecular analysis using the internal transcribed spacers' ITS-1 and ITS-2 of nuclear ribosomal DNA is useful in distinguishing Fasciola species. This study aimed to characterize liver flukes from sheep, goats and cattle using these genetic markers. Fifty nine adult Fasciola specimens were collected from livers of naturally infected sheep, goats and cattle at selected abattoirs in Kisumu, Baringo and Narok Counties. Sequence comparison of ITS-1 and ITS-2 sequences of Fasciola isolates from this study and sequences in Genbank was carried out. A maximum likelihood tree was constructed for phylogenetic analysis. Analysis of ITS- 1 and ITS-2 rDNA sequences revealed that $F$. hepatica and $F$. gigantica caused infection in both cattle and sheep and in goats only F. gigantica caused infection. The sequenced PCR amplicons showed a close relationship between Fasciola species in this study with Fasciola isolates from other regions in the world. Phylogenetic analysis showed that sequences of $F$. hepatica are similar to the sequence from Spain, China and Tunisia obtained from GenBank. The sequences of $F$. gigantica in this study have similarity to the sequence from Iran and Burkina Faso. Data from this study provides information that serves as basis for further studies on the distribution of F. gigantica and F. hepatica in other localities in Kenya, and is also important in designing epidemiological and control programmes for zoonotic fascioliasis.

\section{Introduction}

The most widespread liver flukes are of the genus Fasciola and include two species: Fasciola hepatica and Fasciola gigantica causing fasciolosis (Wongkham et al. 2005), but Fasciola hepatica is majorly prevalent in temperate regions while Fasciola gigantica is commonly distributed in tropical climates (Walker et al. 2008; Yakhchali et al. 2015). Fasciola infection is of veterinary importance, especially in regions majorly practicing sheep or cattle farming, resulting in massive economic burdens (Hussein and Khalifa 2010). The World Health Organization has recognized Fasciola infection as a Neglected Topical Disease due to its public health significance (Takeuchi-Storm et al. 2017; Sah et al. 2018) and is now considered as an emerging infection in different regions of the world, especially in South America, Africa and Asia (Hussein and Khalifa 2010, SalahiMoghaddam and Arfaa 2013).

The two Fasciola species coexist in many African and Asian countries (Sumruayphol et al. 2020), and can also occur in the same region, although ecological factors influence the transmission of trematodes and the abundance of their freshwater snail intermediate host (Mas-Coma et al. 2005). Fasciola parasites can be distinguished using morphological features (Ashrafi et al. 2006), but this can lead to uncertainty in identification of species with intermediate morphological features (Itagaki et al. 2005). Molecular methods have been employed to distinguish between Fasciola hepatica and Fasciola gigantica (Marcilla et al. 2002), these are the most reliable and sensitive methods for the exploration of genetic variability among flukes (Mas-Coma et al. 2007). They are also very useful tools for epidemiological survey and diagnosis of Fasciola species (Mas-Coma et al. 2005).

Molecular analysis was carried out in this study to differentiate adult Fasciola species obtained from naturally infected liver of sheep, goats and cattle at selected slaughter houses within the study area. The nucleotide sequences of the ITS- 1 and ITS- 2 of the nuclear ribosomal DNA (rDNA) of 59 Fasciola worms from Kisumu, Baringo and Narok Counties was determined in order to establish the prevalence of Fasciola species and identify the domestic animal species most infected by Fasciola parasite in the study area.

\section{Materials And Methods Study area}

This study was carried out in Mara river basin in Narok County, Perkera irrigation scheme in Baringo County and Ahero irrigation scheme in Kisumu County, Kenya (Fig. 1). The residents of the study area practice irrigation and livestock farming for both beef and milk production. Perkera irrigation scheme lies in the lowland area with an average altitude of $1100 \mathrm{~m}$ above sea level and covers a total area of 2,350 hectares. The rainfall varies from 1000 to $1500 \mathrm{~mm}$ in the highlands to $600 \mathrm{~mm}$ per annum in the lowlands. The temperatures vary between $25^{\circ} \mathrm{C}$ to $30^{\circ} \mathrm{C}$, however in January the temperatures rises up to $35^{\circ} \mathrm{C}$ on average. The 
Ahero irrigation scheme has an area of $2085.9 \mathrm{Km}^{2}$ and annual relief rainfall between $1200 \mathrm{~mm}$ and $1300 \mathrm{~mm}$ with a mean annual temperature of $23^{\circ} \mathrm{C}$ with a range of between $20^{\circ} \mathrm{C}$ and $35^{\circ} \mathrm{C}$ and the altitude of $1168 \mathrm{~m}$ above sea level. The 13,750 $\mathrm{km}^{2}$ drainage area of the Mara River basin covers the agricultural and forested areas in the upper basin, the open pastureland in the middle portion of the basin and the Masai Mara Game Reserve in Kenya $\left(1718 \mathrm{~km}^{2}\right.$, all of which is within the Mara River Basin). It lies at an altitude range of $1480-2280 \mathrm{~m}$ above sea level. The rainfall is bimodal and the highest annual rainfall amount is received in the high altitude areas with $1100 \mathrm{~mm}$ on the average. Livestock accounts for $30 \%$ of the agriculture in this region.

\section{Source and collection of adult Fasciola samples}

Adult Fasciola specimens were collected from livers of naturally infected sheep, goats and cattle at selected abattoirs in three regions, Perkera Irrigation Scheme, Ahero Irrigation Scheme and Mara River Basin. A total of 59 infected livers were collected from three abattoirs from 20 livers (8 sheep, 12 goats) from Perkera, 19 livers (7 sheep, 12cattle) fromAhero, and 20 livers (7 sheep, 4 goats, 9 cattle) from Narok (Table 1). The livers along with gall bladders including the bile duct of all cattle, sheep and goats slaughtered at the abattoir were thoroughly inspected for the presence of liver flukes and the infected ones were removed from the slaughtered animals. The bile ducts were incised longitudinally through the gall bladder and the parasites were removed with the help of fine forceps, taking all necessary precautions to avoid any damage to the parasite. The infected livers were squeezed manually to macerate the parenchyma and the flukes were carefully removed. A total of 354 of individual isolate were obtained (119 form Perkera, 133 form Ahero and 102 from Narok).All samples were thoroughly washed individually 2 to 3 times in physiological saline to remove debris and host cells, and subsequently fixed in $70 \%$ ethanol and were carried to the laboratory where they were identified as Fasciola species and stored at room temperature for DNA extraction.

Table 1

Location and number of Fasciola specimen used for molecular identification

\begin{tabular}{|llll|}
\hline Location & Host & Species & Number of isolates \\
\hline Perkera & Sheep & F. hepatica & 4 \\
\hline Perkera & Sheep & F.gigantica & 4 \\
\hline Perkera & Goat & F.gigantiga & 12 \\
\hline Ahero & Sheep & F.gigantica & 7 \\
\hline Ahero & Cattle & F.gigantica & 12 \\
\hline Narok & Sheep & F.gigantica & 3 \\
\hline Narok & Sheep & F. hepatica & 4 \\
\hline Narok & Cattle & F.gigantica & 7 \\
\hline Narok & Cattle & F. hepatica & 2 \\
\hline Narok & Goat & F.gigantica & 4 \\
\hline
\end{tabular}

\section{DNA extraction}

One adult fluke from each liver was used for total Genomic DNA was extracted using QIAamp DNA Mini Kits (Qiagen, USA) following the manufacturer's recommendations (Dar et al. 2012). The extracted DNA quality was assessed using $1 \%$ agarose gel examined in UV transilluminator and the bands were visualized and photographed.

\section{PCR amplification}

PCR amplification was performed according to (Yuan et al. 2016). The internal transcribed spacer 1 (ITS1) and Internal transcribed spacer 2 (ITS2), regions were amplified by PCR using a set of BD1 5'-GTCGTAACAAGGTTTCCGTA-3' and BD2 5'TATGCTTAAATTCAGCGGGT-3' as forward and reverse primers, respectively. PCR reaction was performed in a total volume of 50 
$\mu \mathrm{l}$ containing $2 \mu \mathrm{l}$ DNA template, $25 \mu \mathrm{l} 2 \mathrm{x}$ master mix one taq Quick load, $21 \mu \mathrm{l}$ of $\mathrm{ddH}_{2} \mathrm{O}$ and $1 \mu$ of each primer in a thermocycler (BioRad $\left.{ }^{\circledR}\right)$ under the following conditions: $94^{\circ} \mathrm{C}$ for $5 \mathrm{~min}$ as initial denaturation, followed by 30 cycles of $94^{\circ} \mathrm{C}$ for $20 \mathrm{~s}$ (denaturation), $55^{\circ} \mathrm{C}$ for $30 \mathrm{~s}$ (annealing), $72^{\circ} \mathrm{C}$ for $30 \mathrm{~s}$ (extension) and final extension of $72^{\circ} \mathrm{C}$ for $10 \mathrm{~min}$. For detection of PCR results, $5 \mu$ l of the PCR product was examined on $1 \%$ agarose gel in TAE buffer at $80 \mathrm{~V}$ for $45 \mathrm{~min}$. The gels stained with ethidium bromide, visualized and photographed using a transilluminator (UVITEC). To estimate the size of the amplicons, a $100 \mathrm{bp}$ DNA ladder (Fermentas) was used in gels. The PCR products were sequenced (Sanger dideoxy sequencing, Ingaba biotec) from both directions, using the same primers used in the PCR amplication.

\section{Phylogenetic analysis}

The sequences were aligned and compared with those of existing sequences related to Fasciola species ITS1 and ITS2, available in the GenBank, using the BLAST program (https://blast.ncbi.nlm.nih.gov/Blast.cgi). Multiple alignment was performed with data related to Fasciola species from other countries deposited in GenBank, using BioEdit Sequence Alignment Editor Version 7.1.3 software. A maximum likelihood tree was constructed using the MEGA X software and bootstrap analysis using 1,000 replicates (Shafiei et al. 2014; Kumar et al. 2018).

\section{Results}

The PCR amplification of ITS-1 and ITS-2 rDNA yielded fragments of approximately 970 bp in length (Fig. 2). The 59 PCR amplicons of ITS-1 and ITS-2 were subjected to direct sequencing which yielded sequences of $946 \mathrm{bp}$ in length. The sequence was composed of the complete ITS-1 sequence of $422 \mathrm{bp}$, complete $5.8 \mathrm{~S}$ sequence of $158 \mathrm{bp}$, and complete ITS-2 sequence of $366 \mathrm{bp}$. Out of the 59 Fasciola samples sequenced, 17\% were $F$. hepatica and $83 \%$ were F. gigantica, there were no intermediate forms of Fasciola species. Fasciola samples collected from cattle were F. hepatica 2 (9.5\%), F. gigantica 19 (90.5\%), sheep F. hepatica 8 (36.4\%), F. gigantica 14 (63.6\%) and all samples from goats were F. gigantica.

The sequences were deposited in the GenBank database (https://www.ncbi.nlm.nih.gov/genbank/) under the accession numbers MZ396875, MZ396876, MZ396877, MZ396878, MZ396885, MZ396925, MZ396926, MZ396928, MZ396929, MZ3969332 for Fasciola hepatica and MZ396874, MZ396879- MZ396884, MZ396886- MZ396924, MZ396927, MZ396930, MZ396931 Fasciola gigantica. The sequences were aligned with previously published Fasciola ITS-1, 5.8S and ITS-2 sequences retrieved from GenBank accession numbers JF432073, MK321604, JF496711, AM900371, MW046875, JF496709,KJ789338, HM746787, HQ197358, KF543340, AJ853848, JF432072, KJ789364, HM746785, MK321597, JF432075, GQ231547, AM709647, AM850107 and AM709621 (Alasaad et al. 2007; Ali et al. 2008; Farjallah et al. 2009; Rokni et al. 2010; Amor et al. 2011; Galavani et al. 2016; Evack et al. 2020; Omar et al. 2021).

The sequences of ITS-1 showed that $F$. hepatica differed form $F$. gigantica in five variable nucleotides, while the ITS-2 sequences of the examined F. hepatica was different from F. gigantica ITS-2 in seven nucleotides (Table 2). Among the 59 sequenced Fasciola isolates there was no nucleotide variation in the ITS-1 sequences. In ITS-2 sequences there was no nucleotide variation among $F$. hepatica but nucleotide variation was observed at two nucleotides of $F$. gigantica at sequence position 842 and 936 , two and three Fasciola isolates respectively. This indicates the presence of two genotypes of $F$. gigantica isolates that were examines. Sequence variation in position 842 was examined only in Narok among sheep and cattle, while in position 936 it was examined in Fasciola samples from the three localities and it occurred in cattle and goat. 
Table 2

Comparison of nucleotides at variable sites in ITS-1 and ITS-2 sequences of Fasciola from different hosts and geographical locations

\begin{tabular}{|c|c|c|c|c|c|c|c|c|c|c|c|c|c|c|}
\hline \multirow[t]{3}{*}{ Species } & \multicolumn{12}{|c|}{ Variable sites in ITS- 1 and ITS-2 sequences } & \multirow{3}{*}{$\begin{array}{l}\text { Accession } \\
\text { numbers }\end{array}$} & \multirow[t]{3}{*}{ Location } \\
\hline & \multicolumn{12}{|c|}{ ITS-1 ITS-2 } & & \\
\hline & 18 & 108 & 202 & 280 & 300 & 815 & 842 & 854 & 860 & 911 & 918 & 936 & & \\
\hline \multirow{11}{*}{$\begin{array}{l}F . \\
\text { gigantica }\end{array}$} & $\mathrm{T}$ & $\mathrm{T}$ & $\mathrm{T}$ & $A$ & $\mathrm{~T}$ & C & G & $\mathrm{T}$ & $\mathrm{T}$ & - & $A$ & G & JF432073 & Iran \\
\hline & $\mathrm{T}$ & $\mathrm{T}$ & $\mathrm{T}$ & $A$ & $\mathrm{~T}$ & $\mathrm{C}$ & G & $\mathrm{T}$ & $\mathrm{T}$ & - & $A$ & G & MK321604 & Chad \\
\hline & $\mathrm{T}$ & $\mathrm{T}$ & $\mathrm{T}$ & $A$ & $\mathrm{~T}$ & $C$ & G & $\mathrm{T}$ & $\mathrm{T}$ & - & $A$ & G & JF496711 & China \\
\hline & $\mathrm{T}$ & $\mathrm{T}$ & $\mathrm{T}$ & $A$ & $\mathrm{~T}$ & $C$ & G & $\mathrm{T}$ & $\mathrm{T}$ & - & $A$ & G & AM900371 & Niger \\
\hline & $\mathrm{T}$ & $\mathrm{T}$ & $\mathrm{T}$ & $A$ & $\mathrm{~T}$ & $C$ & G & $\mathrm{T}$ & $\mathrm{T}$ & - & $A$ & G & MW046875 & Zimbabwe \\
\hline & $\mathrm{T}$ & $\mathrm{T}$ & $\mathrm{T}$ & $A$ & $\mathrm{~T}$ & C & G & $\mathrm{T}$ & $\mathrm{T}$ & - & $A$ & G & MZ396874 & This study \\
\hline & $\mathrm{T}$ & $\mathrm{T}$ & $\mathrm{T}$ & $A$ & $\mathrm{~T}$ & $C$ & $C$ & $\mathrm{~T}$ & $\mathrm{~T}$ & - & $A$ & G & MZ396918 & This study \\
\hline & $\mathrm{T}$ & $\mathrm{T}$ & $\mathrm{T}$ & $A$ & $\mathrm{~T}$ & $C$ & $C$ & $\mathrm{~T}$ & $\mathrm{~T}$ & - & $A$ & G & MZ396931 & This study \\
\hline & $\mathrm{T}$ & $\mathrm{T}$ & $\mathrm{T}$ & $A$ & $\mathrm{~T}$ & C & G & $\mathrm{T}$ & $\mathrm{T}$ & - & $A$ & $\mathrm{~T}$ & MZ396912 & This study \\
\hline & $\mathrm{T}$ & $\mathrm{T}$ & $\mathrm{T}$ & $A$ & $\mathrm{~T}$ & $C$ & G & $\mathrm{T}$ & $\mathrm{T}$ & - & $A$ & $\mathrm{~T}$ & MZ396916 & This study \\
\hline & $\mathrm{T}$ & $\mathrm{T}$ & $\mathrm{T}$ & $A$ & $\mathrm{~T}$ & C & G & $\mathrm{T}$ & $\mathrm{T}$ & - & $A$ & $\mathrm{~T}$ & MZ396919 & This study \\
\hline \multirow{5}{*}{$\begin{array}{l}\text { F. } \\
\text { hepatica }\end{array}$} & $C$ & $A$ & $C$ & $\mathrm{~T}$ & C & $\mathrm{T}$ & G & C & C & $\mathrm{T}$ & G & G & AM709647 & Spain \\
\hline & C & $A$ & $C$ & $\mathrm{~T}$ & $C$ & $\mathrm{~T}$ & G & C & C & $\mathrm{T}$ & G & G & AM850107 & Niger \\
\hline & C & $A$ & $C$ & $\mathrm{~T}$ & C & $\mathrm{T}$ & G & C & $C$ & $\mathrm{~T}$ & G & G & JF432072 & Iran \\
\hline & C & $A$ & C & $\mathrm{T}$ & C & $\mathrm{T}$ & G & C & $C$ & $\mathrm{~T}$ & $\mathrm{G}$ & G & JF708027 & China \\
\hline & $\mathrm{C}$ & $A$ & $\mathrm{C}$ & $\mathrm{T}$ & C & $\mathrm{T}$ & $G$ & $\mathrm{C}$ & C & $\mathrm{T}$ & $\mathrm{G}$ & $\mathrm{G}$ & MZ396875 & This study \\
\hline
\end{tabular}

Phylogenetic tree was constructed for the analysis of phylogenetic diversity of the liver flukes, using ITS1 and ITS2 sequences of F. gigantica and F. hepatica from this study along with available sequences in GenBank from other regions (Fig. 3).

Fascioloides magna was used as an outgroup GenBank accession number EF534991 (Khalifa et al. 2016).

\section{Discussion}

Fascioliasis is a parasitic disease which is of concern to veterinary and public health sector worldwide (Sy et al. 2021). The genetic markers ITS1 and ITS2 genes of ribosomal DNA have been utilized to discriminate between Fasciola hepatica and Fasciola gigantica (Amor et al. 2011; Dar et al. 2019). There is limited data on the genetic characteristics of Fasciola species in Kenya. Out of the 59 Fasciola samples sequenced, $83 \%$ and $17 \%$ of the isolates were identified as F. gigantica and F. hepatica respectively. In the present study, F. gigantica caused majority of the infection in cattle compared to infection in sheep. Isolates for $F$. hepatica, 8 out of 10 were found in sheep. This was in agreement with studies from other regions of the world that shows F. hepatica are more prevalent in sheep while F. gigantica are more prevalent in cattle (Akhlaghi et al. 2017). A study in Tanzania showed that 41 Fasciola isolates were F. hepatica (Farjallah et al. 2009), in Iran showed that $96.8 \%$ of 31 sheep sampled were infected with F. hepatica (Rokni et al. 2010). A study in Niger also showed that $66.7 \%$ of 12 cattle isolates were $F$. gigantica (Ali et al. 2008). In the past, it was believed that $F$. hepatica was present primarily in the temperate regions, while $F$. gigantica is distributed in some countries in tropical region (Evack et al. 2020). This has been proved not to be the case because several studies have recently documented the presence of $F$. hepatica in Africa and Asia (Amer et al. 2011; Dar et al. 2012; Mucheka et 
al. 2015), including this present study that have shown the existence of both F. hepatica and F. gigantica in the three localities in Kenya. In addition, the present study is the first to demonstrate the presence of Fasciola hepatica in the study areas. This could be attributed to environmental and host-related factors that could affect the distribution of Fasciola flukes (Amer et al. 2016). Among the two Fasciola species, Fasciola hepatica has a selective advantage because it has been reported to adapt quickly to external selection pressures such as new hosts, new environments, and medications than Fasciola gigantica (Cwiklinski et al. 2015).

Alignment of the sequences of ITS- 1 and ITS-2 rDNA with available sequences in GenBank showed ten DNA variable sites in which segregated the Fasciola isolates into two different genotypes, this is consistent with previous studies (Chougar et al. 2019). In this study, the sequences of ITS-1 showed five variable nucleotides that separated between $F$. hepatica from $F$. gigantica and there was no nucleotide variation in the ITS-1 sequences. ITS-2 sequences $F$. hepatica was different from $F$. gigantica in seven nucleotides. Also in ITS-2 sequences there was no nucleotide variation in $F$. hepatica but nucleotide variation was observed at two nucleotides of five F. gigantica at sequence position 842 and 936, two and three Fasciola isolates respectively. This indicates the presence of two genotypes of $F$. gigantica isolates in the three localities.

Phylogenetic tree constructed using ITS1 and ITS2 sequences of $F$. gigantica and $F$. hepatica from this study along with available sequences in GenBank from other regions showed a close relationship between Fasciola species in this study in comparison with Fasciola isolates from other regions in the world. All the sequences of $F$. hepatica are in the same group and are similar to the Fasciola species of Switzerland, Spain, China and Tunisia. The sequence of $F$. gigantica in this study, fall in the same group and are similar to the Fasciola species of Zimbabwe, Iran and Burkina Faso.

\section{Conclusion}

This present study has shown the existence of both F. hepatica and F. gigantica in Kenya. In addition, it is the first to demonstrate the existence of Fasciola hepatica in Narok, Kisumu and Baringo Counties in Kenya. Further studies involving more other mitochondrial polymorphic genes, like cytochrome c oxidase gene (CO1), can be carried out to assist understand more on genetic divergence of both Fasciola gigantica and Fasciola hepatica in the region and other parts of the world. This will also enable the assessment its zoonotic potential and epidemiological surveys especially in areas where there is limited resources making prevention and control strategies difficult to implement and sustain.

\section{Declarations}

\section{Funding information}

This work was supported by the Kenya National Commission for Science, Technology and Innovation [NACOSTI] [grant number NACOSTI/RCD/ST\&I/7 ${ }^{\text {TH }}$ CALL/PhD/168].

\section{Conflicts of interests}

The authors declare that there are no conflicts of interest.

\section{Availability of data and material}

The datasets generated during and/or analysed during the current study are available in the GenBank repository under the following accession numbers [MZ396875-78, MZ396885, MZ396925-26, MZ396928-29, MZ3969332, MZ396874, MZ39689784, MZ396886-924, MZ396927, MZ396930-31], [https://www.ncbi.nlm.nih.gov/nuccore]

\section{Code availability}

Not applicable

\section{Authors' contributions}


Cornelius Kibet Kipyegen designed the project, acquired and analysed data and wrote the first draft of the manuscript. Charle I. Muleke and Elick O. Otachi supervised the research, contributed to writing and reviewing of the manuscript. All authors read and approved the final manuscript.

\section{Ethical approval}

This study was approved by the Egerton University Research and Ethical Committee (EU/RE/DVC/009) and The Kenya National Commission for Science, Technology and Innovation (NACOSTI/P/15/8095/6943). "The authors assert that all procedures contributing to this work comply with the ethical standards of the relevant national and institutional committees on human experimentation and with the Helsinki Declaration 1975, as revised in 2008."

\section{References}

1. Akhlaghi E, Mohammadi MA, Ziaali N, Baneshi MR, Nasibi S, Kamyabi H, Rostami S, Harandi MF (2017) Morphometric and Molecular Study of Fasciola Isolates from Ruminants in Iran. Türkiye Parazitol Derg 41: 192-197. http://doi: 10.5152/tpd.2017.5214

2. Ali H, Ai L, Song HQ, Ali S, Lin RQ, Seyni B et al (2008) Genetic characterization of Fasciola samples from different host species and geographical localities revealed the existence of $F$. hepatica and F. gigantica in Niger. Parasitol Res 102: 10211024. http://doi: 10.1007/s00436-007-0870-7

3. Amer S, Dar Y, Ichikawa M, Fukuda Y, Tada C, Itagaki T, Nakai Y (2011) Identification of Fasciola species isolated from Egypt based on sequence analysis of genomic (ITS1 and ITS2) and mitochondrial (NDI and COI) gene markers. Parasitol Int 60:5-12. http://doi.org/10.1016/j.parint.2010.09.003

4. Amer S, ElKhatam A, Zidan S, Feng Y, Xiao L (2016) Identity of Fasciola spp. in sheep in Egypt. Parasites Vectors 9:623. http://doi.org/10.1186/s13071-016-1898-2

5. Amor N, Halajian A, Farjallah S, Merella P, Said K, Slimane BB (2011) Molecular characterization of Fasciola spp. from the endemic area of northern Iran based on nuclear ribosomal DNA sequences. Exp Parasitol 128:196-204. doi 10.1016/j.exppara.2011.03.011

6. Ashrafi K, Valero MA, Panova M, Periago MV, Massoud J, Mas-Coma S (2006) Phenotypic analysis of adults of Fasciola hepatica, Fasciola gigantica forms from endemic region of Gilan, Iran. Parasitol Int 55(4):249-260. http://doi.org/10.1016/j.parint.2006.06.003

7. Chougar L, Amor N, Farjallah S, Harhoura K, Aissi M, Alagaili AN, Merella P (2019) New insight into genetic variation and haplotype diversity of Fasciola hepatica from Algeria. Parasitol Res 118:1179-1192. https://doi.org/10.1007/s00436-01906270-5

8. Cwiklinski K, Dalton JP, Dufresne PJ, La Course J, Williams DJ, Hodgkinson J, Paterson S (2015) The Fasciola hepatica genome: Gene duplication and polymorphism reveals adaptation to the host environment and the capacity for rapid evolution. Genome Biol 16:71-83. doi 10.1186/s13059-015-0632-2

9. Dar Y, Amer S, Mercier A, Courtioux B, Dreyfuss G (2012) Molecular identification of Fasciola spp. (Digenea: Fasciolidae) in Egypt. Parasite 19:177-182. doi 10.1051/parasite/2012192177

10. Dar JS, Ganai BA, Shahardar RA, Zargar UR (2019) Molecular characterization and Immunodiagnostic potential of various antigenic proteins of Fasciola gigantica species isolated from sheep of North West Himalayan Region. HELMINTHOLOGIA 56(2): 93-107. http://doi:10.2478/helm2019000

11. Evack JG, Remo SS, Sylwia DB, Till SV, Annour AB, Bongo NN, Helena G, Jurg U, Jakob Z, Oliver B (2020) Molecular confirmation of a Fasciola gigantica and Fasciola hepatica hybrid in a Chadian bovine. J Parasitol 106(2):316-322. doi 10.1645/19-66

12. Farjallah S, Sanna D, Amor N, Mehel BB, Piras MC, Merella P et al (2009) Genetic characterization of Fasciola hepatica from Tunisia and Algeria based on mitochondrial and nuclear DNA sequences. Parasitol Research 105:1617-1621.

http://doi:10.1007/s00436-009-1601-z

Page $7 / 11$ 
13. Hussein AA, Khalifa MA (2010) Fascioliasis prevalences among animals and human in Upper Egypt. Journal of King Saud University (Science) 22:15-19. doi:10.1016/j.jksus.2009.12.003

14. Itagaki T, Kikawa M, Terasaki K, Shibahara T, Fukuda K (2005) Molecular characterization of parthenogenic Fasciola sp. in Korea on the basis of DNA sequences of ribosomal ITS1 and mitochondrial NDI gene. Journal of Veterinary Medicine Science 67:1115-1118. doi 10.1292/jvms.67.1115

15. Kumar S, Stecher G, Li M, Knyaz C, Tamura K (2018) MEGA X: Molecular Evolutionary Genetics Analysis across computing platforms. Mol Biol Evol 35:1547-1549. doi 10.1093/molbev/msy096

16. Marcilla A, Bargues MD, Mas-Coma S (2002) A PCRRFLP assay for the distinction between Fasciola hepatica and Fasciola gigantica. Mol Cell Probes 16:327-343. doi 10.1006/mcpr.2002.0429

17. Mas-Coma MS, Bargues MD, Valero MA (2005) Fascioliasis and other plant-borne trematode zoonoses. Int J Parasitol 35(11-12):1255-1278. http://doi.org/10.1016/j.ijpara.2005.07.010

18. Mas-Coma S, Bargues MD, Valero MA (2007) Plant-Borne Trematode Zoonoses: Fascioliasis and Fasciolopsiasis. In: Murrel KD, Fried B (eds) Food-borne Parasitic Zoonosis: Fish and Plant-borne Parasites, 11th edn. Springer, New York, pp 293-335

19. Mucheka V, Lamb J, Pfukenyi D, Mukaratirwa S (2015) DNA sequence analyses reveal co-occurrence of novel haplotypes of Fasciola gigantica with F. hepatica in South Africa and Zimbabwe. Veterinary Parasitology 214:144-151. doi 10.1016/j.vetpar.2015.09.024

20. Rokni MB, Mirhendi H, Behnia M, Harandi MF, Jalalizand N (2010) Molecular characterization of Fasciola hepatica isolates by RAPD-PCR and ribosomal ITS1 sequencing. Iranian Red Crescent Medical Journal 12(1):27-32

21. Sah R, Khadka S, Lakhey PJ, Pradhan S, Shah NP, Singh YP, Mas-Coma S (2018) Human case of Fasciola gigantica-like infection, review of human fascioliasis reports in Nepal, and epidemiological analysis within the South Central Asia. Acta Parasitologica 63(3):435-443. doi 10.1515/ap-2018-0053

22. Salahi-Moghaddam A, Arfaa F (2013) Epidemiology of Human Fascioliasis Outbreaks in Iran. Journal Archives Military Medicine 1:6-12. doi 10.5812/jamm.13890

23. Shafiei R, Sarkari B, Sadjjadi SM, RezaMowlavi G, Moshfe A (2014) Molecular and Morphological Characterization of Fasciola spp. Isolated from Different Host Species in a Newly Emerging Focus of Human Fascioliasis in Iran. Veterinary Medicine International. http://dx.doi.org/10.1155/2014/405740

24. Sumruayphol S, Siribat P, Dujardin J-P, Dujardin S, Komalamisra C, Thaenkham U (2020) Fasciola gigantica, F. hepatica and Fasciola intermediate forms: geometric morphometrics and an artificial neural network to help morphological identification. PeerJ 8:e8597. http://doi.org/10.7717/peerj.8597

25. Sy I, Margardt L, Ngbede EO, Adah MI, Yusuf ST, Keiser J, Rehner J, Utzinger J, Poppert S, Becker SL (2021) Identification of Adult Fasciola spp. Using Matrix-Assisted Laser/Desorption Ionization Time-of-Flight (MALDI-TOF) Mass Spectrometry. Microorganisms 9:82. https://doi.org/10.3390/microorganisms9010082

26. Takeuchi-Storm N, Denwood M, Hansen TVA, Halasa T, Rattenborg E, Enemark HL, Thamsborg SM (2017) Farm-level risk factors for Fasciola hepatica infection in Danish dairy cattle as evaluated by two diagnostic methods. Parasites Vectors 10:555. http://doi:10.1186/s13071-017-2504-y

27. Walker SM, Makundi AE, Namuba FV, Kassuku AA, Hoey EM, Prodohl P, Thard JR, Trudgett A (2008) The distribution of Fasciola hepatica and Fasciola gigantica within southern Tanzania - constraints associated with the intermediate host. Parasitology 135:495-503. http://doi:10.1017/S0031182007004076

28. Wongkham C, Tantrawatpan C, Intapan PM, Maleewong W, Wongkham S, Nakashima K (2005) Evaluation of Immunoglobulin G Subclass Antibodies against Recombinant Fasciola gigantica Cathepsin L1 in an Enzyme-Linked Immunosorbent Assay for Serodiagnosis of Human Fasciolosis. Clinical and Diagnostic Laboratory Immunology 12: 1152-1156. doi: 10.1128/CDLI.12.10.1152-1156

29. Yakhchali M, Malekzadeh-Viayeh R, Imani-Baran A, Mardani K (2015) Morphological and molecular discrimination of Fasciola species isolated from domestic ruminants of Urmia City, Iran. Iran J Parasitol: 10(1):46-55

30. Yuan W, Liu J-M, Lu K, Li H, Duan M-M, Hong Y, Liu Y-P, Zhou Y, Tong L-B, Lu J, Feng J-T, Zhu C-G, Jin Y-M, Cheng G-F, Lin J$J(2016)$ Molecular identification and seasonal infections of species of Fasciola in ruminants from two provinces in China. 


\section{Figures}

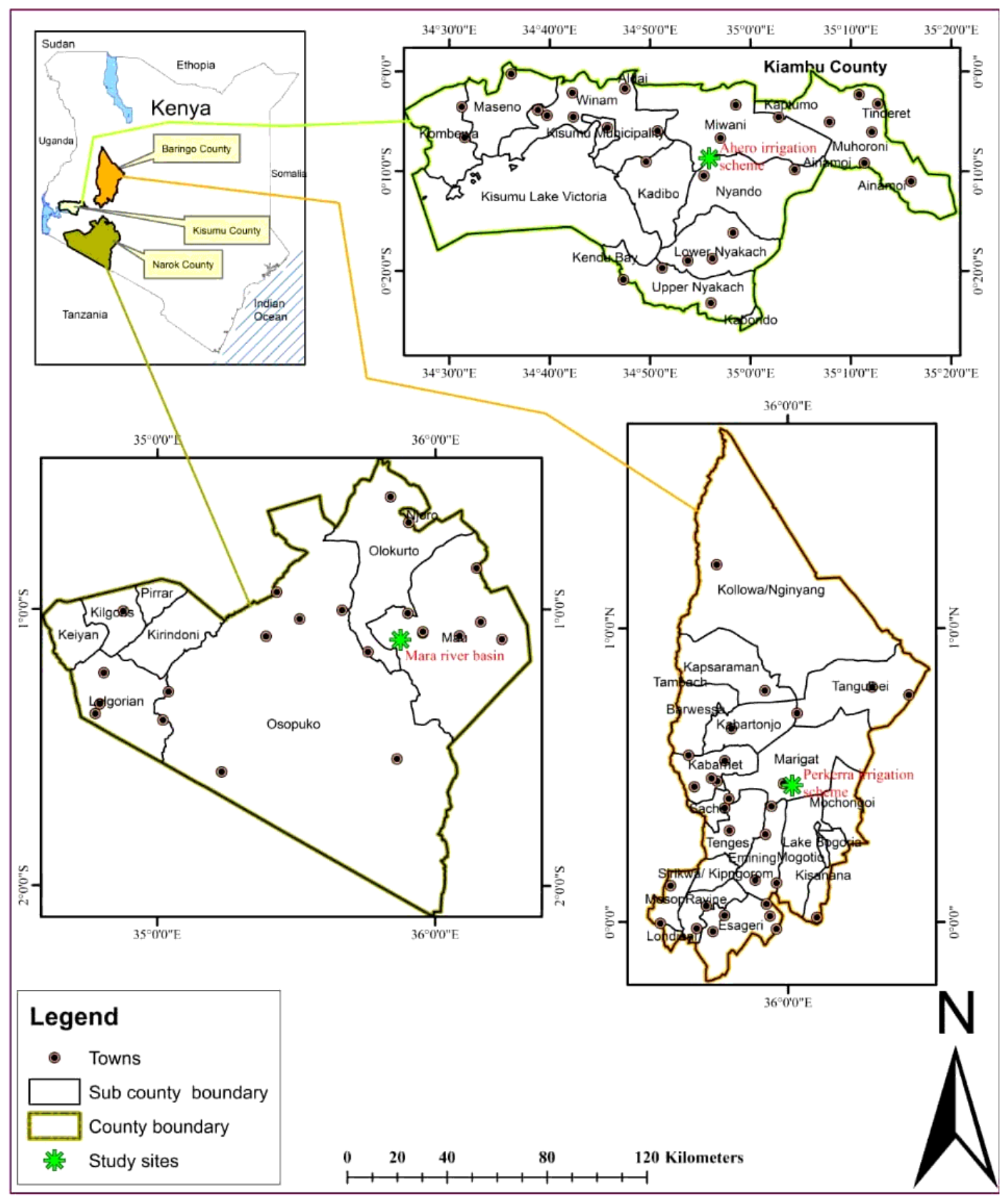

Figure 1

A map of Kenya showing the location of Narok, Ahero and Baringo Counties, where the samples were collected. Source: Kenya: County Fact Sheet (2013). Commission on Revenue Allocation, Second edition 


\section{$\begin{array}{lllllllllll}1 & 2 & 3 & 4 & 5 & 6 & 7 & 8 & 9 & 10 & 11\end{array}$}

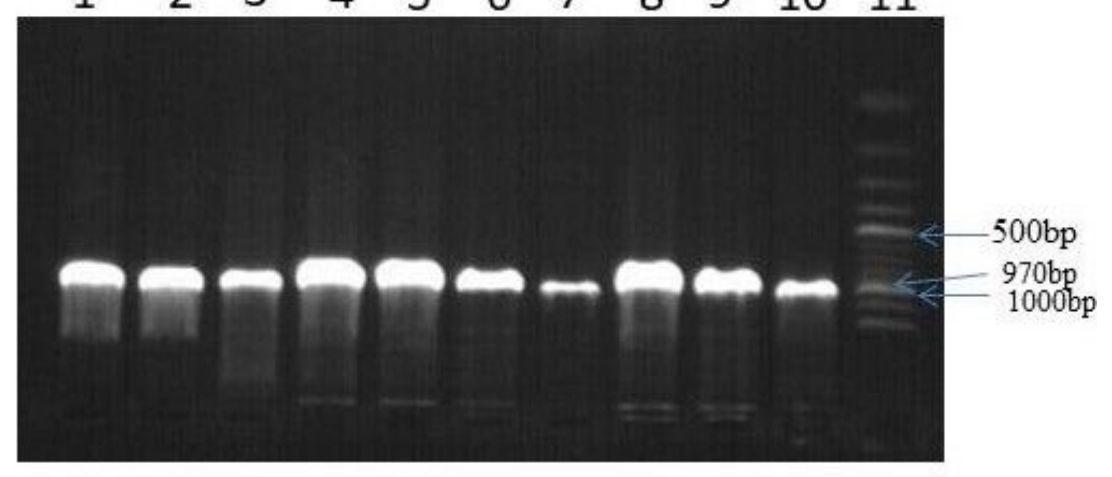

Figure 2

Agarose gel electrophoresis of ITS-1 and ITS-2 rDNA of Fasciola specimen. Well 1- 10 Fasciola species samples, well 11 is DNA ladder of $1 \mathrm{~kb}$ molecular weight 


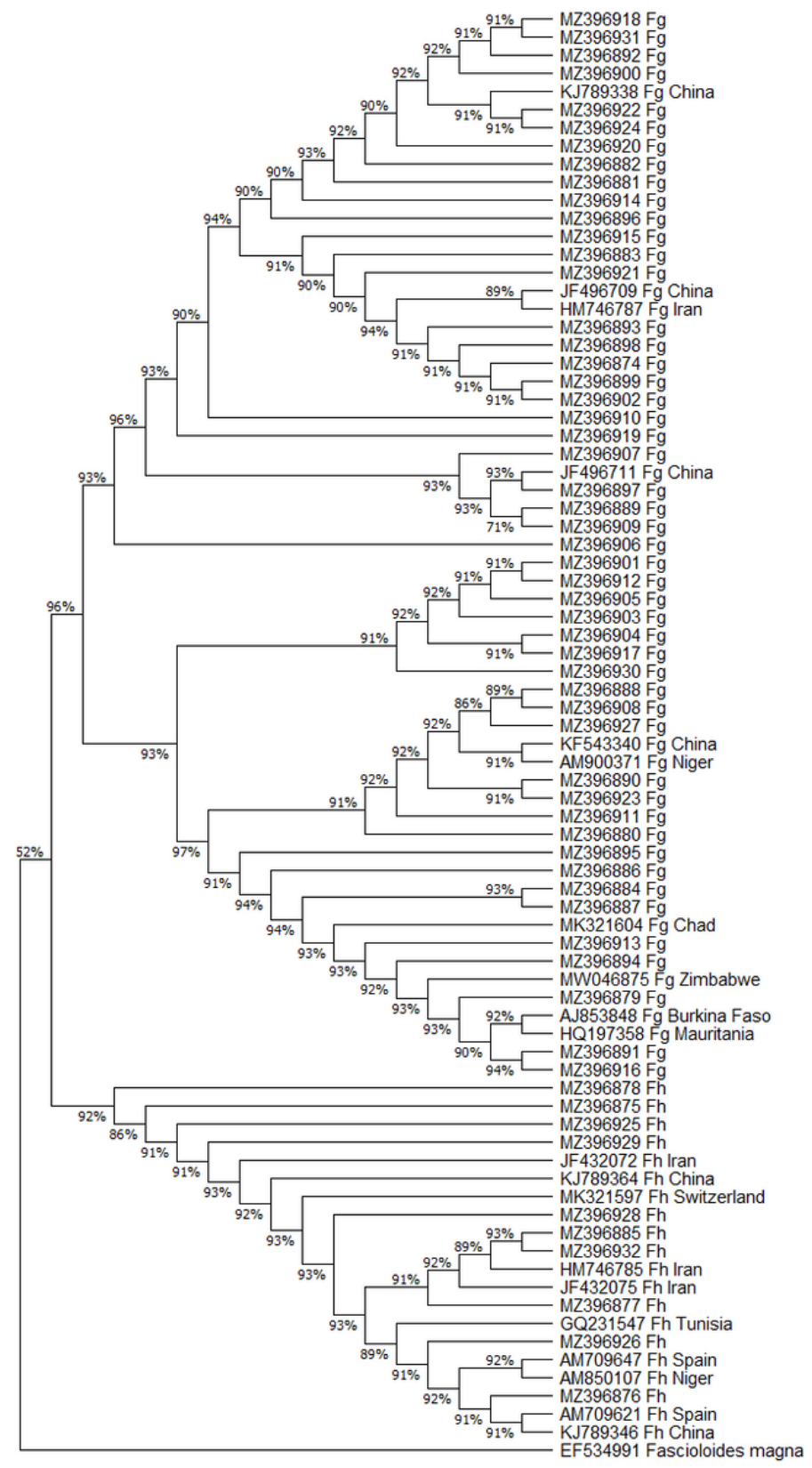

\section{Figure 3}

Phylogenetic relationship of ITS-1 and ITS-2 rDNA sequences of isolates of Fasciola hepatica (MZ396875-78, MZ396885, MZ396925-26, MZ396928-29, MZ3969332) and Fasciola gigantica (MZ396874, MZ396879-MZ396884, MZ396886-MZ396924, MZ396927, MZ396930-31) specimens collected from sheep, goat and cattle in Kenya and other representative isolates of F. gigantica and F. hepatica from different regions using Maximum Likelihood method. Phylogenetic tree was obtained using MEGA X [Kumar et al, 2018] with bootstrap values of 1000 replicates set for neighbor-joining. 